\title{
Association of systemic and ocular risk factors with neurosensory retinal detachment in diabetic macular edema: a case-control study
}

\author{
Aditi Gupta', Rajiv Raman', Vaitheeswaran Kulothungan² and Tarun Sharma ${ }^{1 *}$
}

\begin{abstract}
Background: Diabetic macular edema (DME) with neurosensory retinal detachment (NSD) remains an important cause of visual loss in patients with diabetes. The aim of the study was to elucidate the association of systemic and ocular risk factors with NSD in DME.

Methods: In a retrospective case-control study, we reviewed clinical records of all the subjects with DME seen between January 2010 and December 2010. Cases and controls were selected based on optical coherence tomography and stereoscopic biomicroscopy review. NSD was defined as subfoveal fluid accumulation under detached retina with or without overlying foveal thickening. The association between the presence of NSD, blood pressure, lipid status and various other biochemical parameters was evaluated.

Results: Group I (cases) included 37 eyes of 33 patients having DME with NSD and Group II (controls) included 30 eyes of 21 patients having DME without NSD. Patients ranged in age (mean \pm SD) from 50 to 62 years (56.6 +/-6.78) for cases and from 51 to 65 years $(58.4+/-7.84)$ for controls. The duration of diabetes ranged from 4 to 15 year (mean 9.45+/-6.08) among cases and 4 to 14 years (9.7+/-5.12) among controls. Significant risk factors for NSD were high values of systolic and diastolic blood pressure ( $p=0.039$ and 0.043 respectively).
\end{abstract}

Conclusion: High systolic and diastolic blood pressures are independent and significant risk factors for NSD in DME. Keywords: Diabetic macular edema, Neurosensory retinal detachment, Risk factors, Blood Pressure

\section{Background}

Diabetic macular edema (DME) remains a major cause of visual loss in patients with diabetes [1]. Optical coherence tomography (OCT) has specifically been used for characterizing the morphological features of DME, and five OCT patterns of DME have been described: diffuse retinal thickening (DRT), cystoid macular edema (CME), neurosensory retinal detachment (NSD) without posterior hyaloidal traction, posterior hyaloidal traction (PHT) without tractional retinal detachment (TRD) and PHT with TRD [2-5]. NSD under the fovea has been reported in $3-31 \%$ of patients with DME [2,4-10].

The prognosis of DME is decided by many factors, such as the presence of NSD, inner segment/outer segment

\footnotetext{
*Correspondence: drtaruns@gmail.com

'Shri Bhagwan Mahavir Department of Vitreoretinal Services, Sankara Nethralaya, 18, College Road, Chennai 600 006, Tamil Nadu, India Full list of author information is available at the end of the article
}

(IS/OS) conjunction and integrity of the external limiting membrane (ELM) line [11-13]. IS/OS integrity and intact ELM are important indicators in the evaluation of foveal photoreceptor layer integrity, and correlate strongly with best-corrected visual acuity (BCVA) after medical or surgical treatment of DME [11,12].

The presence of NSD is found to adversely affect the prognosis of DME. NSD can significantly limit effective laser treatment of the macula [14]. The presence of NSD in DME associated with subretinal exudation has been reported to be associated with poor visual prognosis after vitrectomy [2]. Likewise, in macular edema secondary to branch retinal vein occlusion, the presence of subfoveal NSD was shown to retard the absorption of macular edema and recovery of vision after grid laser photocoagulation [14]. The high percentage of NSD in CRVO [9] may have played a role in the poor response of macular edema to grid laser photocoagulation in the multicenter trial on

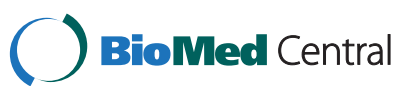


CRVO by the Central Retinal Vein Occlusion Study Group [15]. Hence, the need to better understand the pathogenesis of NSD has been stressed [15]. Although previous studies have extensively reported the systemic and ocular risk factors for the presence of DME [16-20], the risk factors associated with NSD in DME have been rarely studied in detail [21]. A recent study indicated the presence of high glycosylated hemoglobin (HbA1c) as a risk factor for NSD, suggesting the role of systemic factors in the causation of NSD in DME [21]. The aim of this study was to elucidate the association of various systemic and ocular risk factors with NSD in Indian subjects with DME.

\section{Methods}

This study was a retrospective chart review of patients with diagnosed DME seen between Jan 2010 to Dec 2010. Cases and controls were selected based on SD-OCT review. Group I (cases) included 37 eyes of 33 patients who were diagnosed as DME with NSD on OCT and Group II (controls) included 30 eyes of 21 patients who had DME without NSD. The macular edema was diagnosed by biomicroscopy according to the criteria reported by ETDRS. NSD type DME was defined as subfoveal fluid accumulation with distinct outer border of detached retina with or without overlying foveal thickening (Figure 1). All cases had NSD associated with DRT or CME (Figure 1). All controls had DRT or CME without any NSD (Figure 2). Patients with posterior hyaloidal traction (PHT) without TRD and PHT with TRD as documented on OCT, and media opacities such as corneal opacity, dense cataract, vitreous or preretinal hemorrhage, uveitis were excluded from the study. This study was approved by the Institutional Review Board, Vision Research Foundation and adhered to the Declaration of Helsinki. The medical records of all the patients including cases and controls were reviewed, with documentation of patients' age, gender, duration and type of diabetes mellitus, history of any associated systemic disease like hypertension, hyperlipidemia, nephropathy, ischemic heart disease status post coronary artery bypass surgery, details of systemic medications, history of ocular surgeries including intravitreal injections and laser treatment in the past. The details of patients' ocular examination findings including BCVA on Snellen chart (later converted to logMAR for statistical analyses), lens status, stage of diabetic retinopathy, OCT findings, and systemic biochemical parameters were also noted. A prototype SD-OCT system (Topcon 3D1000, Tokyo, Japan) was used with an axial resolution of $6 u$ and acquisition rate of approximately 18,000 scans per second. All OCT images were acquired through a dilated pupil. During the OCT examination, macula was scanned on six radial sections including the horizontal, vertical and oblique planes through the centre of the fovea. The retinal thickness was measured as distance of vitreoretinal interface and inner edge of retinal pigment epithelium (RPE) at the maximum point of edema. Central subfield retinal thickness was also noted on OCT.

The blood pressure was recorded, in the sitting position, in the right arm to the nearest $2 \mathrm{~mm} \mathrm{Hg}$ using the mercury sphygmomanometer (Diamond Deluxe BP apparatus, Pune, India). Two readings were taken with a five minutes interval and their mean indication was taken as the blood pressure. In most of the subjects, the blood pressure measurement was taken on the day of complete ophthalmic examination which included OCT. In the remaining subjects, blood pressure was measured on the day of OCT review which was 1 or 2 days later. The biochemical

A: NSD with DRT

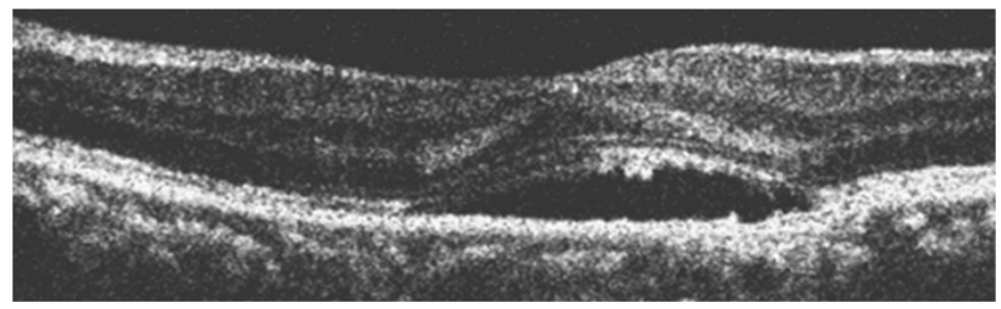

B: NSD with CME

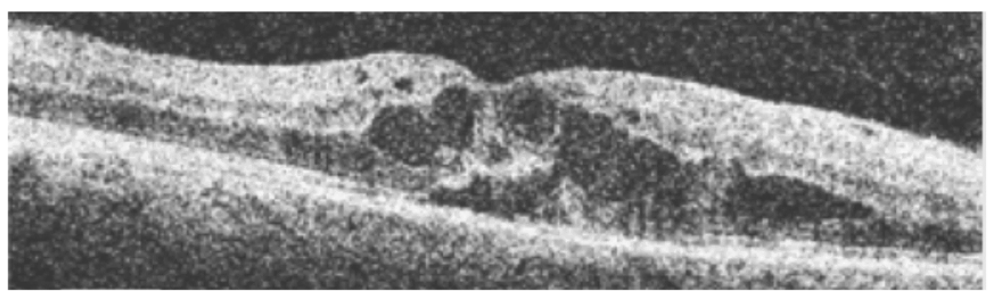

Figure 1 Spectral domain OCT shows diffuse retinal thickening $(A)$ and hyporeflective cystic spaces in the inner retina suggestive of cystoid macular edema (B) with associated subfoveal neurosensory detachment. 


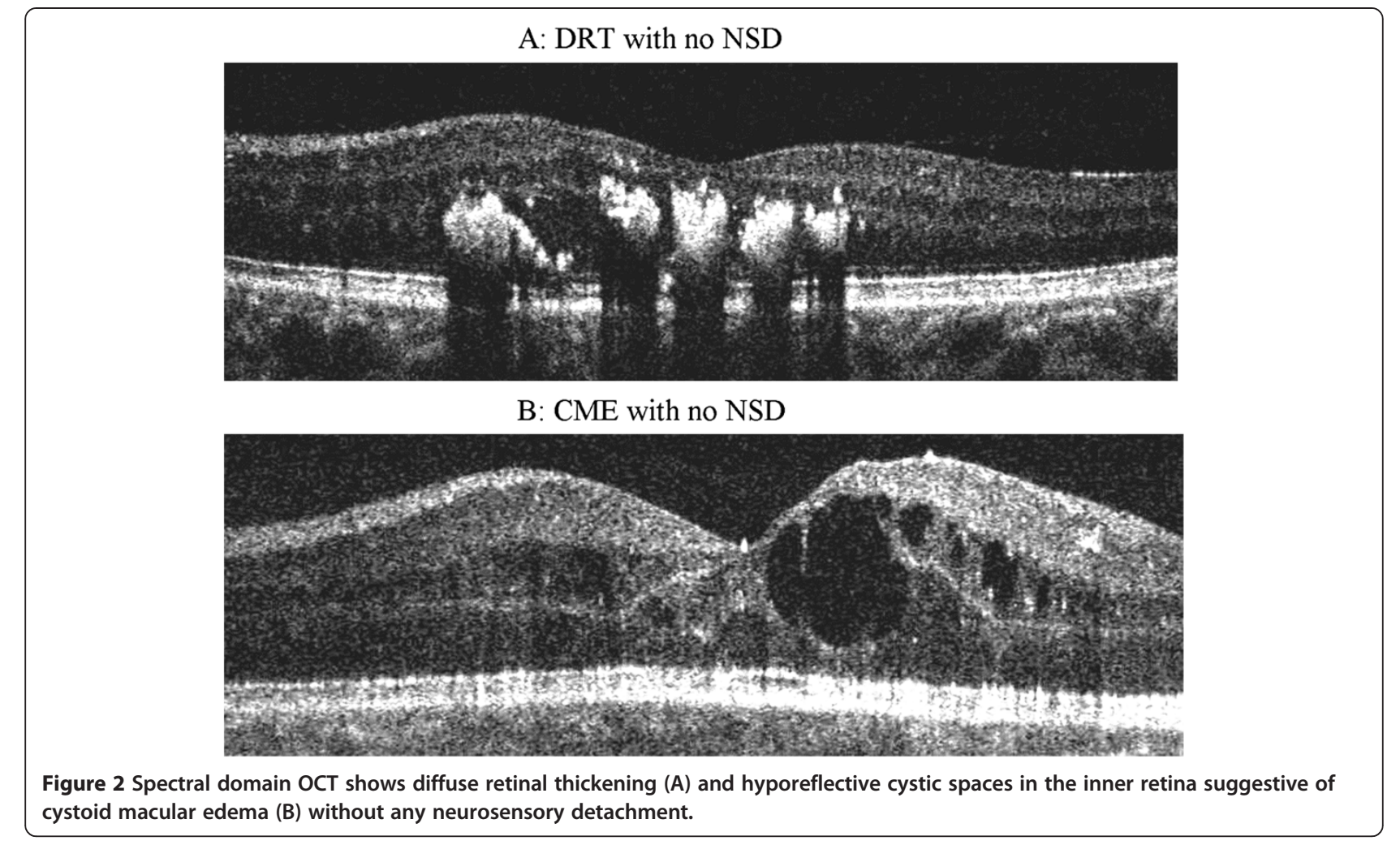

parameters noted were fasting and post-prandial blood sugar levels, hemoglobin, glycosylated hemoglobin, blood pressure and renal function tests (serum urea and serum creatinine). All biochemical parameters were done at same laboratory using standard techniques. The grading of diabetic retinopathy was done based on modified klein classification as mild, moderate and severe nonproliferative diabetic retinopathy and proliferative diabetic retinopathy [22]. The modification was proposed as a standardized alternative to the more detailed Early Treatment Diabetic Retinopathy Study (ETDRS) system. It involves grading seven stereoscopic standard fields as a whole, and assigning a level of severity for the eye according to the greatest degree of retinopathy using a modified Airlie House Classification scheme [22].

\section{Statistical analysis}

A computerized database was created for all the records. Statistical analyses were performed using SPSS Windows version 14.0 (SPSS Science, Chicago, IL, USA). All the data were expressed as mean \pm S.D or as percentage. The normality of distribution was checked for all factors by Kolmogorov-Smirnov analysis. The data in the study followed normal distribution, hence we used the parametric tests to determine significance. Chi-square test was used to compare proportions among neurosensory detachment status with the independent categorical variables and the Student's $t$-test was used to compare proportions among neurosensory detachment status with the independent measured (continuous) variables in Univariate analyses. $P$ value less than 0.05 was considered significant. Multivariate analyses could not be done because of small sample size in both the groups.

\section{Results}

A total of 37 eyes of 33 patients who had NSD with DME (Group 1, cases) and 30 eyes of 21 patients who had DME without NSD (Group 2, controls) were included in our study. All patients included were of type 2 diabetes mellitus. The patients ranged in age from 50 to 62 years among the cases (mean $56.6+/-6.7$ ) and 51 to 65 among the controls (mean 58.4+/7.84). The duration of diabetes ranged from 4 to 15 years (mean $9.45+/-6.08$ ) among cases and 4 to 14 years $(9.7+/-5.12)$ among controls. Group 1 included 28 males (84.8\%) and 5 females (15.2\%) and Group 2 included 14 males (67.7\%) and 7 females (33.3\%).

Table 1 depicts the comparison of systemic factors associated with cases and controls. There were no significant differences in the two groups in terms of the mean age $(\mathrm{p}=0.375)$, duration of diabetes $(\mathrm{p}=0.876)$, fasting blood sugar and post prandial blood sugar levels $(\mathrm{p}=$ 0.959 and 0.436 respectively), glycosylated hemoglobin $(\mathrm{p}=0.859)$, hemoglobin $(\mathrm{p}=0.118)$ and presence of hypertension $(\mathrm{p}=0.634)$. However, the mean systolic and diastolic blood pressures were significantly higher $(\mathrm{p}=0.039$ 
Table 1 Comparison of systemic features amongst cases and controls

\begin{tabular}{|c|c|c|c|}
\hline & $\begin{array}{l}\text { Cases } \\
\text { (33 patients) }\end{array}$ & $\begin{array}{l}\text { Controls } \\
\text { (21 patients) }\end{array}$ & $P$ value \\
\hline Age (years) & $56.6+/-6,78$ & $58.4+/-7.84$ & 0.375 \\
\hline \multicolumn{4}{|l|}{ Gender n (\%) } \\
\hline Males & 28 (84.8\%) & $14(66.7 \%)$ & \\
\hline Females & $5(15.2 \%)$ & 7 (33.3\%) & \\
\hline $\begin{array}{l}\text { Duration of diabetes } \\
\text { (years) }\end{array}$ & $9.45+/-6.08$ & $9.7+/-5.12$ & 0.876 \\
\hline \multicolumn{4}{|l|}{$\begin{array}{l}\text { Systemic } \\
\text { associations } n(\%)\end{array}$} \\
\hline Hypertension & $24(72.7 \%)$ & $14(66.7 \%)$ & 0.634 \\
\hline Hyperlipidemia & $3(9.1 \%)$ & $1(4.8 \%)$ & 1.000 \\
\hline Nephropathy & $1(3 \%)$ & 0 & 1.000 \\
\hline$S / p C A B G$ & $1(3 \%)$ & 0 & 1.000 \\
\hline \multicolumn{4}{|l|}{$\begin{array}{l}\text { Systemic } \\
\text { medications n (\%) }\end{array}$} \\
\hline Antidiabetic insulin & $3(9.1 \%)$ & $3(14.3 \%)$ & 0.667 \\
\hline Group 1 (biguanides) & 7 (21.2\%) & $9(42.9 \%)$ & 0.089 \\
\hline Group 2 (glitazones) & $5(15.2 \%)$ & $1(4.8 \%)$ & 0.386 \\
\hline Group 3 (sulfonylureas) & 22 (66.7\%) & $14(66.7 \%)$ & 1.000 \\
\hline Antihypertensive & $18(54.6 \%)$ & $10(47.6 \%)$ & 0.619 \\
\hline \multicolumn{4}{|l|}{$\begin{array}{l}\text { Mean value of } \\
\text { systemic parameters }\end{array}$} \\
\hline $\mathrm{HbA} 1 \mathrm{c}$ & $6.73+/-1.42$ & $6.71+/-1.39$ & 0.859 \\
\hline $\mathrm{SBP}(\mathrm{mm} \mathrm{Hg})$ & $147.84+/-11.33$ & $141+/-11.88$ & 0.039 \\
\hline $\mathrm{DBP}(\mathrm{mm} \mathrm{Hg})$ & $85.24+/-5.98$ & $81.47+/-7.29$ & 0.043 \\
\hline FBS (mg\%) & $144.05+/-81.59$ & $142.94+/-70.42$ & 0.959 \\
\hline PPBS (mg\%) & $229.17+/-112.52$ & $208.15+/-60.97$ & 0.436 \\
\hline Urea & $37.82+/-17.0$ & $34.52+/-19.0$ & 0.509 \\
\hline Creatinine & $1.41+/-0.74$ & $1.07+/-0.331$ & 0.053 \\
\hline Hemoglobin (g\%) & $10.71+/-2.36$ & $11.77+/-2.44$ & 0.118 \\
\hline
\end{tabular}

S/P CABG: Status post coronary artery bypass graft, HbA1c: Glycosylated hemoglobin, SBP: Systolic blood pressure, DBP: Diastolic blood pressure, FBS: fdasting blood sugar, PPBS: Post prandial blood sugar.

$P$ value $<0.05$ considered significant (boldface).

and 0.043 respectively) in the NSD group than the control group.

Table 2 compares the ocular factors among eyes with NSD and control eyes. The mean log MAR BCVA was $0.822+/-0.421$ in NSD group and $0.61+/-0.47$ in the control group (p 0.056). The mean central macular thickness as determined by OCT was higher in cases than in the controls $(485.7+/-189.81$ versus $332.2+/-134.14$ microns, $\mathrm{p}=0.0004)$. Cystoid macular edema was more commonly seen than diffuse edema in NSD group, although the difference was not significant $(p=0.085) .35 .1 \%$ of eyes with NSD had associated proliferative diabetic retinopathy compared to $23.3 \%$ in the control group ( $\mathrm{p}=0.820)$. There were no significant differences in the two groups in terms
Table 2 Comparison of ocular findings amongst cases and controls

\begin{tabular}{|c|c|c|c|}
\hline & $\begin{array}{l}\text { Cases } \\
\text { ( } 37 \text { eyes) }\end{array}$ & $\begin{array}{l}\text { Controls } \\
\text { (30 eyes) }\end{array}$ & $P$ value \\
\hline $\begin{array}{l}\text { Mean BCVA } \\
\text { (logMAR) }\end{array}$ & $0.822+/-0.421$ & $0.61+/-0.470$ & 0.056 \\
\hline $\begin{array}{l}\text { Mean CMT } \\
\text { (microns) }\end{array}$ & $485.7+/-189.81$ & $332.2+/-134.14$ & 0.0004 \\
\hline \multicolumn{4}{|l|}{$\begin{array}{l}\text { Type of } \\
\text { edema } n(\%)\end{array}$} \\
\hline CME & 25 (67.6\%) & $14(46.7 \%)$ & 0.085 \\
\hline Diffuse & $12(32.4 \%)$ & 16 (53.3\%) & \\
\hline \multicolumn{4}{|l|}{$\begin{array}{l}\text { Stage of } \\
\text { DR } n(\%)\end{array}$} \\
\hline Mild NPDR & 0 & $6(20 \%)$ & 0.820 \\
\hline Moderate NPDR & $15(40.5 \%)$ & $15(50 \%)$ & \\
\hline Severe NPDR & $9(24.3 \%)$ & $2(6.7 \%)$ & \\
\hline PDR & $13(35.1 \%)$ & 7 (23.3\%) & \\
\hline \multicolumn{4}{|l|}{$\begin{array}{l}\text { Phakic status } \\
\text { n (\%) }\end{array}$} \\
\hline Phakic & 33 (89.2\%) & 29 (96.7\%) & 0.370 \\
\hline Aphakic & 0 & 0 & \\
\hline Pseudophakic & $4(10.8 \%)$ & 1 (3.3\%) & \\
\hline $\begin{array}{l}\text { Ocular surgery } \\
\text { (includes anti VEGF } \\
\text { injections) } n(\%)\end{array}$ & 19 (51.4\%) & $6(20 \%)$ & 0.008 \\
\hline S/P PRP n (\%) & 12 (32.4\%) & $6(20 \%)$ & 0.254 \\
\hline
\end{tabular}

of pseudophakic status $(\mathrm{p}=0.370)$. As expected, ocular surgery including anti- VEGF injections were performed more frequently in Group 1 ( $\mathrm{p}=0.008)$.

\section{Discussion}

DME remains the leading cause of visual loss among patients with diabetes mellitus. Among the various patterns of DME, NSD under the fovea has been reported in 3$31 \%$ of patients. The pathogenesis of NSD is linked not only to the limitations of the draining vascular system, but also to impairment in the function of the RPE. Kang et al. reported that in diabetic eyes, the incidence of CME and NSD increasd with the existence of retinal vascular hyperpermeability and the pathology of these two phenomena might share a common pathogenesis in this regard [4].

Various systemic factors have been associated with increased incidence of DME like severity of diabetic retinopathy, poor glycemic control and duration of diabetes. Hypertension, proteinuria, dyslipidemia, uncontrolled renal parameters, and PRP for PDR (causing acute choroidal ischemia), have also been associated with increased risk of 
DME. Although all these factors are known to correlate with increased incidence of DME, very few studies have correlated the presence of uncontrolled systemic disease and biochemical parameters with increased incidence of NSD in DME. Poor control of systemic factors could be related to increased leakage from the capillaries with loss of vascular integrity as well to an impaired function of RPE. One study demonstrated the presence of high HbA1c levels in the patients with diabetic CME and NSD, compared to those with diabetic CME and no associated NSD [21]. In our study, we did not find a significant association between HbA1c and presence of NSD. Instead, only high mean systolic and diastolic blood pressures were found to be independent and significant risk factors for NSD in DME.

Increased blood pressure has been implicated, through the effects of increased blood flow, to cause damage to the retinal capillary endothelial cells in eyes of diabetic patients [23]. Elevated blood pressure also alters the retinal arteriolar hemodynamics, causing a reduction in the compliance (i.e., an increase of vascular rigidity) of the arteriolar circulation with increasing risk of DME [20]. Hypertension is a well recognized cause of NSD preferentially affecting the macular region, although NSD is more commonly accompanied with malignant hypertension $[24,25]$. The occurrence of NSD in DME can be secondary to excessive leakage in retina or to a poorly functioning RPE. Raised blood pressure can lead to increased retinal leakage as well as ischemic damage to RPE. Another possibility is that diabetes may have caused subclinical choroidal vascular damage in diabetic subjects, rendering the circulatory system more susceptible to further ischemic insult by raised blood pressure.

Choroidal vascular damage causes ischemic damage to the RPE and leads to breakdown of the blood-retinal barrier with transudation of fluid into subretinal space. Hayreh observed that the presence of NSD was correlated to the degree of choroidal circulation disruption. Fluid overload has also been implicated as a cause of NSD [26].

Anemia is another known risk factor for DME. Low hemoglobin levels can occur in diabetic patients secondary to renal disease or can occur independently. However, the renal disease as measured by serum urea and creatinine was not found to be associated with NSD in this study. Futhermore, anemia was not found as an independent risk factor for formation of NSD. Low hemoglobin has been described as an independent baseline risk factor in the EDTRS for the development of DME and severe visual loss [27]. Other studies have corroborated this finding [18] and have also found improvement in the DME status following correction of anemia [28-30]. Correction of anemia (and also supplementation of erythropoietin) was noted to decrease the effects of retinopathy with structural improvement, possibly through improved oxygenation of the macula [28]. Singh et al. noted spontaneous closure of microaneurysms in diabetic retinopathy with treatment of co-existing anemia [30]. Friedman et al. reported that increased hematocrit may improve visual acuity due to resolution of macular edema in diabetic retinopathy [29]. Over the past few years, growing evidence supports the hypothesis that hypoxia contributes to progression of tissue injury in diabetic individuals [31]. In our study, although the patients with NSD had lower hemoglobin, none of them had significantly low hemoglobin levels which could be clinically called as anemia. This could be the reason why we were unable to find any significant effect of anemia on NSD.

\section{Conclusion}

In conclusion, we found high systolic and diastolic blood pressures to be independent and significant risk factors for NSD in DME. The present study suggests that the treating ophthalmologists should get a complete systemic workup done for the presence of co-morbidities especially high blood pressure in subjects with NSD in DME. Achieving adequate metabolic control of associated conditions should be aimed in such subjects. Prospective studies are warranted to see whether decreasing the blood pressure of the patient will help in the resolution of NSD in DME.

\section{Competing interests}

The authors declare that they have no competing interests.

\section{Authors' contributions}

AG carried out the data collection, data analysis, and drafted the manuscript. RR conceived the study, and participated in its design and coordination and helped to draft the manuscript. VK helped in data collection, data analysis and performed the statistical analysis. TS helped to conceive the study, supervised the entire study and helped to draft the manuscript. All authors read and approved the final manuscript.

\section{Acknowledgements}

We acknowledge the support of RD Tata Trust, Mumbai, for this project.

\section{Author details}

${ }^{1}$ Shri Bhagwan Mahavir Department of Vitreoretinal Services, Sankara Nethralaya, 18, College Road, Chennai 600 006, Tamil Nadu, India.

2Department of Preventive Medicine and Biostatistics, Sankara Nethralaya, 18, College Road, Chennai 600 006, Tamil Nadu, India.

Received: 7 October 2013 Accepted: 4 April 2014

Published: 9 April 2014

\section{References}

1. Fong DS, Ferris FL, Davis MD, Chew EY: Causes of severe visual loss in the early treatment diabetic retinopathy study: ETDRS report no. 24. Early Treatment Diabetic Retinopathy Study Research Group. Am J Ophthalmol 1999, 127:137-141.

2. Otani T, Kishi S, Maruyama Y: Patterns of diabetic macular edema with optical coherence tomography. Am J Ophthalmol 1999, 127:688-693.

3. Yamamoto S, Yamamoto T, Hayashi M, Takeuchi S: Morphological and functional analyses of diabetic macular edema by optical coherence tomography and multifocal electroretinograms. Graefes Arch Clin Exp Ophthalmol 2001, 239:96-101. 
4. Kang SW, Park CY, Ham DI: The correlation between fluorescein angiographic and optical coherence tomographic features in clinically significant diabetic macular edema. Am J Ophthalmol 2004, 137:313-322.

5. Kim NR, Kim YJ, Chin HS, Moon YS: Optical coherence tomographic patterns in diabetic macular oedema: prediction of visual outcome after focal laser photocoagulation. Br J Ophthalmol 2009, 93:901-905.

6. Network DRCR, Browning DJ, Glassman AR, Aiello LP, Beck RW, Brown DM, Fong DS, Bressler NM, Danis RP, Kinyoun JL, Nguyen QD, Bhavsar AR Gottlieb J, Pieramici DJ, Rauser ME, Apte RS, Lim Jl, Miskala PH: Relationship between optical coherence tomography-measured central retinal thickness and visual acuity in diabetic macular edema. Ophthalmology 2007, 114:525-536.

7. Yeung L, Lima VC, Garcia P, Landa G, Rosen RB: Correlation between spectral domain optical coherence tomography findings and fluorescein angiography patterns in diabetic macular edema. Ophthalmology 2009, 116:1158-1167.

8. Ozdek SC, Erdinc MA, Gürelik G, Aydin B, Bahçeci U, Hasanreisoğlu B: Optical coherence tomographic assessment of diabetic macular edema: comparison with fluorescein angiographic and clinical findings. Ophthalmologica 2005, 219:86-92.

9. Ozdemir H: Serous macular detachment in diabetic cystoid macular oedema. Acta Ophthalmol Scand 2005, 83:63-66.

10. Koleva-Georgieva D, Sivkova N: Assessment of serous macular detachment in eyes with diabetic macular edema by use of spectraldomain optical coherence tomography. Graefes Arch Clin Exp Ophthalmol 2009, 247:1461-1469.

11. Shin HJ, Lee SH, Chung H, Kim HC: Association between photoreceptor integrity and visual outcome in diabetic macular edema. Graefes Arch Clin Exp Ophthalmol 2012, 250:61-70.

12. Chhablani JK, Kim JS, Cheng L, Kozak I, Freeman W: External limiting membrane as a predictor of visual improvement in diabetic macular edema after pars plana vitrectomy. Graefes Arch Clin Exp Ophthalmol 2012, 250:1415-1420.

13. Otani T, Yamaguchi $Y$, Kishi S: Correlation between visual acuity and foveal microstructural changes in diabetic macular edema. Retina 2010, 30:774-780

14. Ohashi H, Oh H, Nishiwaki H, Nonaka A, Takagi H: Delayed absorption of macular edema accompanying serous retinal detachment after grid laser treatment in patients with branch retinal vein occlusion. Ophthalmology 2004, 111:2050-2056.

15. Kokame GT: Editorial. Newly recognized serous macular detachment in retinal vascular disease. Retina 2006, 26:493-494.

16. Sachdev N, Sahni A: Association of systemic risk factors with the severity of retinal hard exudates in a north Indian population with type 2 diabetes. J Postgrad Med 2010, 56:3-6.

17. Asensio-Sánchez VM, Gómez-Ramírez V, Morales-Gómez I, Rodríguez-Vaca I: Clinically significant diabetic macular edema: systemic risk factor. Arch Soc Esp Oftalmol 2008, 83:173-176.

18. Ajoy Mohan VK, Nithyanandam S, Idiculla J: Microalbuminuria and low hemoglobin as risk factors for the occurrence and increasing severity of diabetic retinopathy. Indian J Ophthalmol 2011, 59:207-210.

19. Singh R, Abhiramamurthy V, Gupta V, Gupta A, Bhansali A: Effect of multifactorial intervention on diabetic macular edema. Diabetes Care 2006, 29:463-464.

20. Guan K, Hudson C, Wong T, Kisilevsky M, Nrusimhadevara RK, Lam WC, Mandelcorn M, Devenyi RG, Flanagan JG: Retinal hemodynamics in early diabetic macular edema. Diabetes 2006, 55:813-818.

21. Turgut B, Gul FC, Ilhan N, Demir T, Celiker U: Comparison of serum glycosylated hemoglobin levels in patients with diabetic cystoid macular edema with and without serous macular detachment. Indian J Ophthalmol 2010, 58:381-384.

22. Kohner EM: Diabetic retinopathy. Br Med Bull 1989, 45:148-173.

23. Olson JL, Prall FR, Ciardella AP: Bilateral foveal neurosensory detachment in hypertensive retinopathy demonstrated by optical coherence tomography. Eye 2006, 20:1370-1371.

24. Wolfensberger TJ, Tufail A: Systemic disorders associated with detachment of the neurosensory retina and retinal pigment epithelium. Curr Opin Ophthalmol 2000, 11:455-461.

25. Klein R, Klein BE, Magli YL, Brothers RJ, Meuer SM, Moss SE, Davis MD: An alternative method of grading diabetic retinopathy. Ophthalmology 1986, 93:1183-1187.
26. Ciardella AP: Partial resolution of diabetic macular oedema after systemic treatment with furosemide. Br J Ophthalmol 2004, 88:1224-1225.

27. Davis MD, Fisher MR, Gangnon RE, Barton F, Aiello LM, Chew EY, Ferris FL 3rd, Knatterud GL: Risk factors for high-risk proliferative diabetic retinopathy and severe visual loss: Early Treatment Diabetic Retinopathy Study Report \#18. Invest Ophthalmol Vis Sci 1998, 39:233-252.

28. Berman DH, Friedman EA: Partial absorption of hard exudates in patients with diabetic end-stage renal disease and severe anemia after treatment with erythropoietin. Retina 1994, 14:1-5.

29. Friedman EA, Broom CD, Brown MD, Berman DH: Erythropoietin in diabetic macular edema and renal insufficiency. Am J Kidney Dis 1995, 26:202-208.

30. Singh R, Gupta V, Gupta A, Bhansali A: Spontaneous closure of micro-aneurysms in diabetic retinopathy with treatment of co-existing anemia. Br J Ophthalmol 2005, 89:248-249.

31. Williamson JR, Chang K, Frangos MY: Hyperglycemic pseudohypoxia and diabetic complications. Diabetes 1993, 42:801-813.

doi:10.1186/1471-2415-14-47

Cite this article as: Gupta et al:: Association of systemic and ocular risk factors with neurosensory retinal detachment in diabetic macular edema: a case-control study. BMC Ophthalmology 2014 14:47.

\section{Submit your next manuscript to BioMed Central and take full advantage of:}

- Convenient online submission

- Thorough peer review

- No space constraints or color figure charges

- Immediate publication on acceptance

- Inclusion in PubMed, CAS, Scopus and Google Scholar

- Research which is freely available for redistribution

Submit your manuscript at www.biomedcentral.com/submit
C Biomed Central 